\title{
Fuzzy Controller Considering of Historical State of Error
}

\author{
Weijia Guo ${ }^{1, a}$, Shujie $\mathrm{Li}^{2, \mathrm{~b}}$, Zhigang $\mathrm{Li}^{3, \mathrm{c}}$ \\ ${ }^{1}$ Qian'an College, North China University of Science and Technology, Qian'an,064400, China \\ ${ }^{2}$ College of Electrical Engineering, North China University of Science and \\ Technology, Tangshan,063009, China \\ ${ }^{3}$ Information Engineering College, North China University of Science and \\ Technology,Tangshan,063009, China \\ aemail: kaixinmao100@126.com, bemail: Isjie@heuu.edu.cn, ${ }^{\mathrm{c} e m a i l}$ : heutlzg@163.com
}

Keywords: FFOTS; Historical State of Error; Control Rule

\begin{abstract}
To improve the performance of fuzzy controller, take the historical state of error into account while setting the control rules. Firstly make a rule table (basic rule table) which considers of the current error and error change rate only, secondly, think of all the possible historical state of error on adjacent three sampling points. For every historical state of the error, combine with the error and error change rate of the current sampling spot; make a rule table based on the basic rule table. Finally check the effectiveness of the method by MATLAB simulation. The simulation shows that the method of taking the historical state of the error helps to decrease the steady-state error, decrease the overshoot, decrease the adjust time.
\end{abstract}

\section{Introduction}

There are many shortcomings in regular fuzzy controller. Such as steady-state precision is lower, self adapting ability is limited, the factors considering in the fuzzy controller is little, especially the adjust speed and the vibration near the steady point [1]. There are many solutions to the shortcomings of the regular fuzzy controller. Applied methods among them can be divided into two groups. One is optimization on control rules [2] [3]; the other is improvement on the structure of the fuzzy controller [4] [5] [6].

In the article, a new kind fuzzy controller is created by introducing the historical state of the error in the regular fuzzy controller, which is called FFOTS [7]. Generally speaking, the historical state of the error can reflect the trend of the output in a way. In order to better the system performance, combine it with the current state of the output while setting control rules. In the article, control rules in the basic rule table are revised according to the historical state of the error.

\section{Relation between the Historical State of the Error and the System Output}

The model of the regular fuzzy controller is shown in Fig.1.

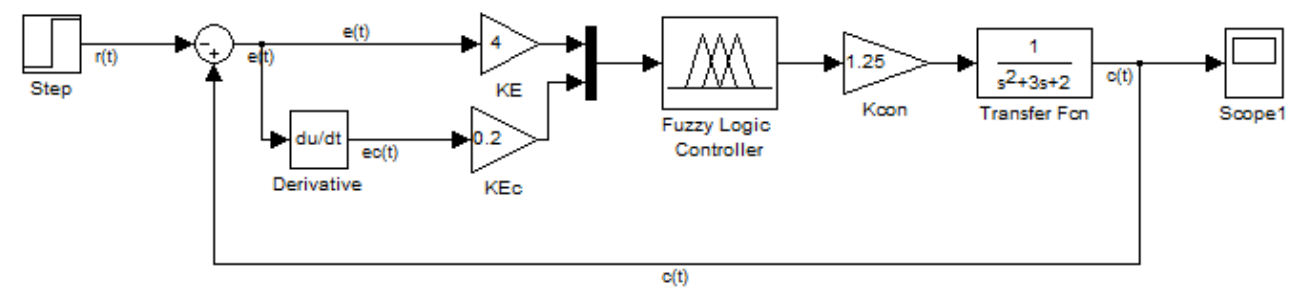

Fig.1 Regular fuzzy controller model

In Fig. $1 \mathrm{e}(\mathrm{t})$ is error , $\mathrm{c}(\mathrm{t})$ is system output , $\mathrm{r}(\mathrm{t})$ is the input of the system.

$\mathrm{e}(\mathrm{t})=\mathrm{c}(\mathrm{t})-\mathrm{r}(\mathrm{t})$

It is not enough only considering both the historical state of the error and the current error change rate (EC) while setting control rules, it is necessarily to consider the current error (E). Now 
the work will be converted into making a control rule table for each historical state of the error. The historical state of the error is the same as the historical state of the system output. So the question becomes making a control rule table for each historical state of the system output.

\section{Setting of Control Rule Table}

How to make control rule table for each historical state of the system output? Firstly make a rule table (basic rule table) which considers of the current error and error change rate only. While considering the historical state of the system output, just need revise some rules in the basic rule table. The basic rule table is shown in table 1.

Table 1 Basic rule table

\begin{tabular}{|c|c|c|c|c|c|c|c|}
\hline$\frac{\mathrm{CON}}{\mathrm{E}} \mathrm{EC}$ & NB & NM & NS & $\mathrm{ZO}$ & PS & $\mathrm{PM}$ & PB \\
\hline NB & PB & PB & PB & PB & PB & PM & PS \\
\hline NM & $\mathrm{PB}$ & $\mathrm{PB}$ & $\mathrm{PB}$ & $\mathrm{PB}$ & PM & PS & $\mathrm{ZO}$ \\
\hline NS & $\mathrm{PM}$ & $\mathrm{PM}$ & $\mathrm{PM}$ & PS & $\mathrm{ZO}$ & $\mathrm{ZO}$ & NS \\
\hline $\mathrm{ZO}$ & PM & PS & PS & $\mathrm{ZO}$ & NS & NS & NM \\
\hline PS & PS & $\mathrm{ZO}$ & $\mathrm{ZO}$ & NS & NM & NM & $\mathrm{NM}$ \\
\hline PM & $\mathrm{ZO}$ & NS & NM & NM & NM & NB & $\mathrm{NB}$ \\
\hline $\mathrm{PB}$ & NS & NM & NB & NB & NB & NB & $\mathrm{NB}$ \\
\hline
\end{tabular}

Secondly, let's think of the possible historical state. We need to use adjacent three sampling points. Possible historical states is shown in Fig.2

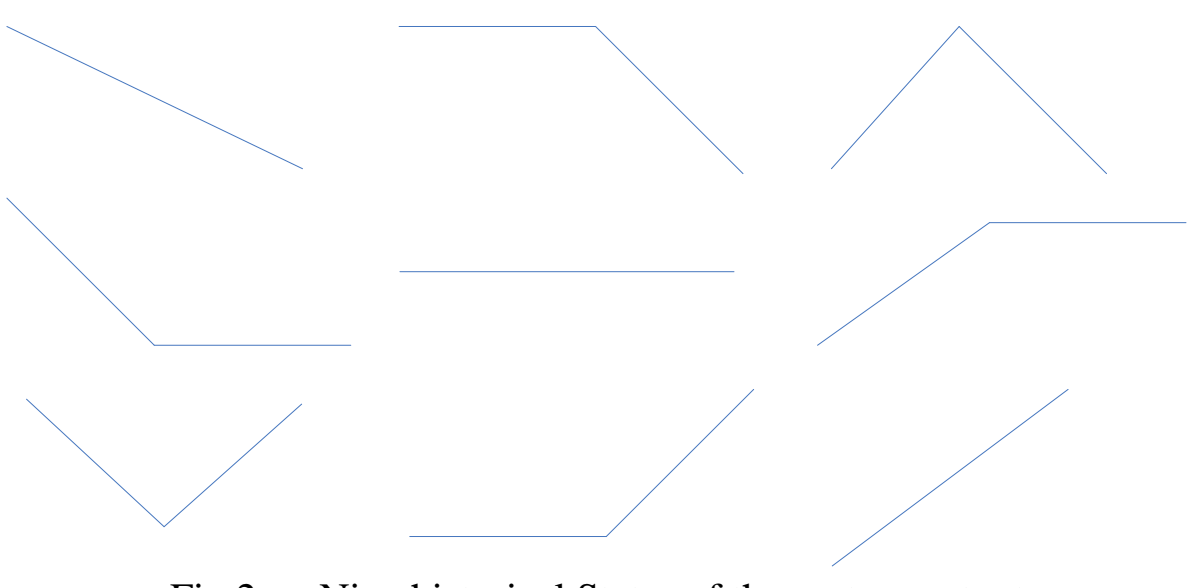

Fig.2 Nine historical States of the system output

The figures in Fig.2 only stand for different historical state. The principle of revising control rules is adjusting CON to make the output moving rapidly towards the setting value. The control rule tables below only contain possible control rules.

When the historical state is minus four, the control rules are shown in table 2.

Table 2 Rule table when the historical state is minus four

\begin{tabular}{|c|c|c|c|c|c|c|c|}
\hline CON EC & NB & NM & NS & ZO & PS & PM & PB \\
\hline NB & PB & PB & PB & PM & PS & ZO & NS \\
\hline NM & PB & PB & PB & PM & ZO & NS & NM \\
\hline NS & PB & PB & PB & PM & ZO & NM & NB \\
\hline ZO & PB & PB & PM & PM & NS & NM & NB \\
\hline
\end{tabular}


When the historical state is minus three, the control rules are shown in table 3.

Table 3 Rule table when the historical state is minus three

\begin{tabular}{|c|c|c|c|c|c|c|c|}
\hline EON EC & NB & NM & NS & ZO & PS & PM & PB \\
\hline ZO & PB & PB & PS & PS & NM & NB & NB \\
\hline
\end{tabular}

When the historical state is minus two, the control rules are shown in table 4.

Table 4 Rule table when the historical state is minus two

\begin{tabular}{|c|c|c|c|c|c|c|c|}
\hline CON EC & NB & NM & NS & ZO & PS & PM & PB \\
\hline PS & PB & PM & ZO & NS & NM & NB & NB \\
\hline PM & PM & PS & ZO & NS & NM & NB & NB \\
\hline PB & PS & ZO & NS & NM & NB & NB & NB \\
\hline
\end{tabular}

When the historical state is minus one, the control rules are shown in table 5.

Table 5 Rule table when the historical state is minus one

\begin{tabular}{|c|c|c|c|c|c|c|c|}
\hline CON EC & NB & NM & NS & ZO & PS & PM & PB \\
\cline { 1 - 7 } NB & PB & PB & PB & PM & PS & ZO & NM \\
\hline NM & PB & PB & PB & PS & ZO & NM & NB \\
\hline NS & PB & PB & PB & PS & ZO & NB & NB \\
\hline
\end{tabular}

When the historical state is zero, the control rules are shown in table 6.

Table 6 Rule table when the historical state is zero

\begin{tabular}{|c|c|c|c|c|c|c|c|}
\hline EON EC & NB & NM & NS & ZO & PS & PM & PB \\
\hline ZO & PB & PB & PB & PS & NM & NB & NB \\
\hline
\end{tabular}

When the historical state is one, the control rules are shown in table 7.

Table 7 Rule table when the historical state is one

\begin{tabular}{|c|c|c|c|c|c|c|c|}
\hline EON EC & NB & NM & NS & ZO & PS & PM & PB \\
\hline PS & PB & PM & ZO & NS & NB & NB & NB \\
\hline PM & PM & PS & ZO & NS & NB & NB & NB \\
\hline PB & PS & ZO & NS & NM & NB & NB & NB \\
\hline
\end{tabular}

When the historical state is two, the control rules are shown in table 8.

Table 8 Rule table when the historical state is two

\begin{tabular}{|c|c|c|c|c|c|c|c|}
\hline CON EC & NB & NM & NS & ZO & PS & PM & PB \\
\hline NB & PB & PB & PB & PM & PS & ZO & NS \\
\hline NM & PB & PB & PB & PS & ZO & NS & NM \\
\hline NS & PB & PB & PB & PS & ZO & NM & NB \\
\hline
\end{tabular}

When the historical state is three, the control rules are shown in table 9.

Table 9 Rule table when the historical state is three

\begin{tabular}{|c|c|c|c|c|c|c|c|}
\hline EON EC & NB & NM & NS & ZO & PS & PM & PB \\
\hline ZO & PB & PB & PM & ZO & NM & NB & NB \\
\hline
\end{tabular}


When the historical state is four, the control rules are shown in table 10.

Table 10 Rule table when the historical state is four

\begin{tabular}{|c|c|c|c|c|c|c|c|}
\hline EON EC & NB & NM & NS & ZO & PS & PM & PB \\
\hline PS & PB & PM & PS & ZO & NB & NB & NB \\
\hline PM & PB & PM & PS & NS & NB & NB & NB \\
\hline PB & PM & PS & PS & NS & NB & NB & NB \\
\hline
\end{tabular}

\section{Test Fuzzy Controller by MATLAB Simulation}

In the simulation, for the new fuzzy controller (FFOTS) which considering the historical state of the error has three inputs: the historical state of error on adjacent three sampling points, E and EC of the current point.

For FFOTS, the control rule table is selected as the principle below: compare the historical state of the error with the nine models in Fig.2, if matched, then use the control rule table associated with current model, else compare with the next model until success.

Both regular fuzzy controller and FFOTS have many common parameters. The common parameters are as follows: the distribution of fuzzy subsets in E, EC and CON; quantization factor in $\mathrm{E}$ and $\mathrm{EC}$, proportion factor in CON. In the test, the expectation value of CON is one. The models of the two fuzzy controllers are shown in Fig.3.

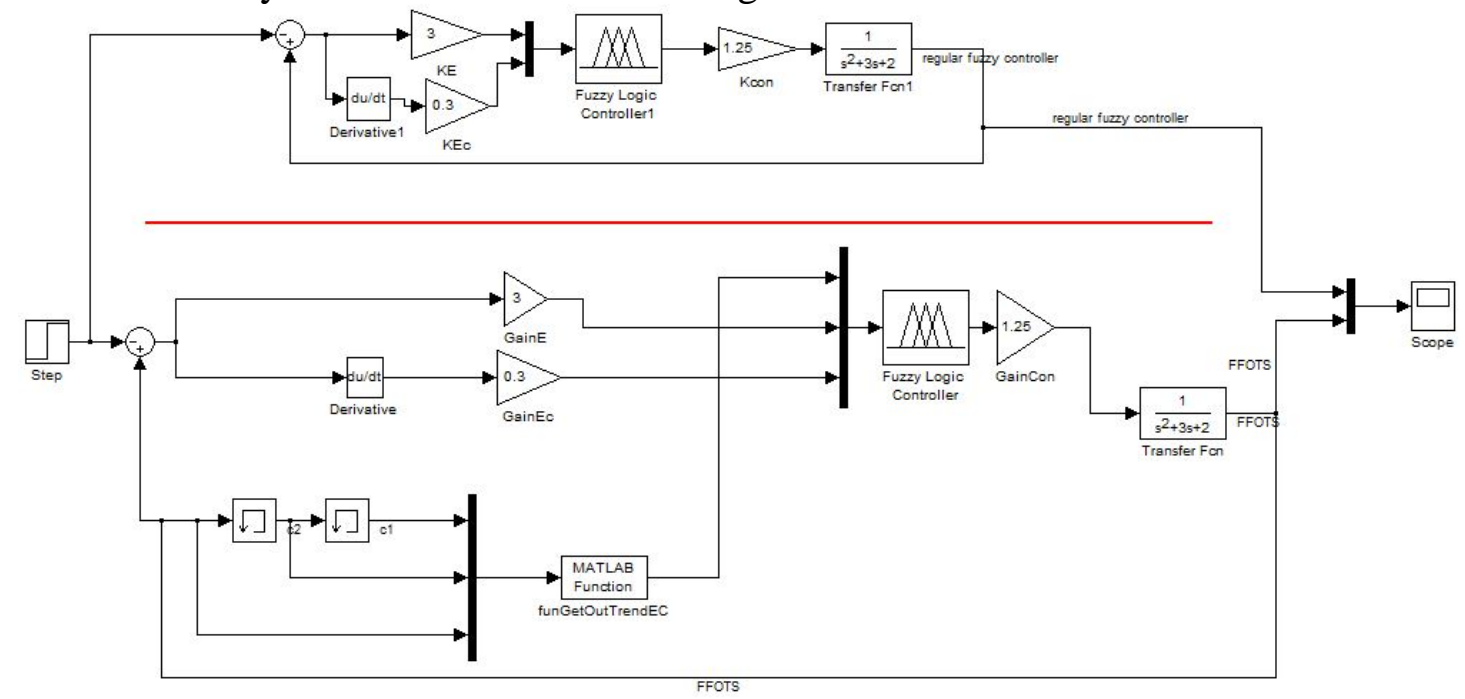

Fig.3 the models of regular fuzzy controller and FFOTS

In Fig.3, the model above is regular fuzzy controller, the model below is FFOTS. The outputs of the two models are shown in Fig.4. 


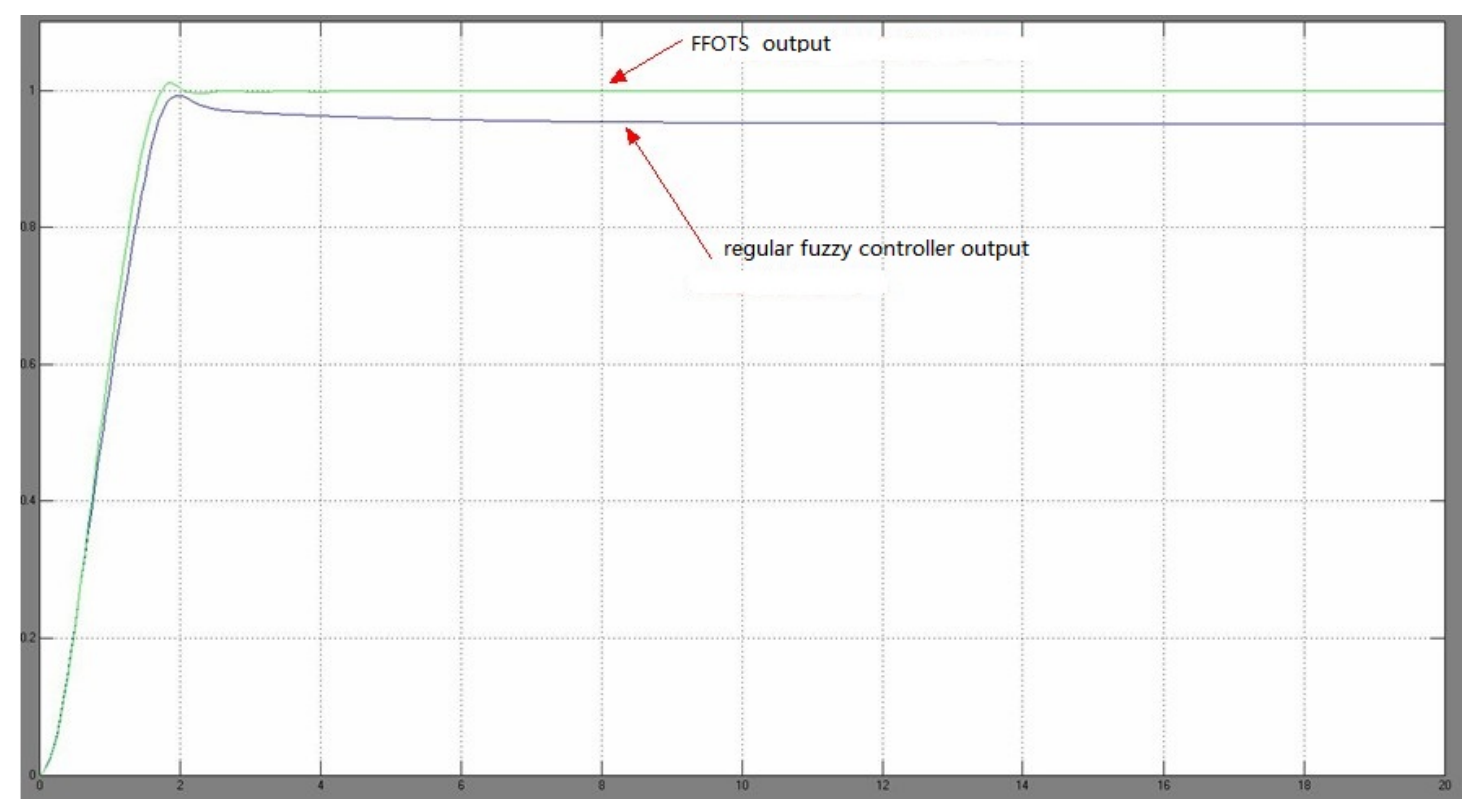

Fig.4 the outputs of regular fuzzy controller and FFOTS

In Fig. 4, the line above is the output of FFOTS, the other line is the output of the regular fuzzy controller. It is obviously that the performance of FFOTS is better than the regular fuzzy controller. In the test, the maximum error is $2 \%$ of the expectation value of the output. The static performance index and the dynamic performance index [8] are shown in table 11.

Table 11 The performance index compare of FFOTS with the regular fuzzy controller

\begin{tabular}{|c|c|c|c|c|c|}
\hline Model name & $\begin{array}{c}\text { Static } \\
\text { error }\end{array}$ & Overshoot & Rise time & $\begin{array}{c}\text { Adjust } \\
\text { time }\end{array}$ & Oscillation count \\
\hline FFOTS & 0.001 & $1.2 \%$ & $1.73 \mathrm{~s}$ & $1.65 \mathrm{~s}$ & 1 \\
\hline $\begin{array}{c}\text { Regular fuzzy } \\
\text { controller }\end{array}$ & 0.05 & $4.48 \%$ & $1.68 \mathrm{~s}$ & $2.72 \mathrm{~s}$ & 1 \\
\hline
\end{tabular}

\section{Conclusion}

The test above shows that the FFOTS is better than the regular fuzzy controller in static error, overshoot and adjust time. The FFOTS is only worse than the regular fuzzy controller in rise time. On the whole, the FFOTS is better than the regular fuzzy controller. This is obvious in Fig.4.

\section{Acknowledgement}

In this paper, the research was sponsored by the Nature Science Foundation of Hebei Province (Project No. F2013209203)

\section{References}

[1] Yang Sai, Ren Jinxia. Application of Improved Fuzzy Controller in Industrial Course[J]. Transaction of Jiangxi University of Science and Technology, 2009, 30(4):26-28

[2] Huang Liming, Tang Chaohui. Acquirement of Fuzzy Expert Control Rules in Intelligent Control Course [J]. Computer Engineering and Applications, 2007, 43(13): 239-242.

[3] Li Zhigang, Wang Zhenlei. A New Clustering Analysis Used for Generating Fuzzy Control Rules[C] . The 5th International Conference on Fuzzy Systems and Knowledge Discovery, 2008:26-32.

[4] Wang Weihua. Expert Fuzzy Control of Single-Stage Inverted Pendulum [J]. Transaction of Hubei University (Nature Science Version), 1996, 21(2):117-120. 
[5] Wang Chuanzhong, Yang Xia, Li Qiang. Research of Expert-Servo-System Using Variable Structure System with Fuzzy Sliding Formwork [J]. Transaction of Hebei University Of Technology, 2001, 30(5):52-55.

[6] Ma Ruiping, Xu Hualong, Xiao Fan. A Method of Computing Firing Data of Ballistic Missile Based on Improved Fuzzy Control [J]. Journal of Projectiles, Rockets, Missiles and Guidance, 2010, 30(3):125-134.

[7] Li,Zhigang ,Chen,Long. A Study on Generation of Fuzzy Control Rules Based on FFOTS[C].2013 25th Chinese Control and Decision Conference, p2230-2233

[8] Gu Shusheng, Wang Jianhui. Automatic Control Principle [M]. Beijing: Metallurgical Industry Press, 2001:8-11. 